\section{Antibacterial and antiviral potential of neuropeptides}

Carla Zannella, Debora Stelitano, Veronica Folliero, Luciana Palomba, Tiziana Francesca Bovier, Roberta Astorri, Annalisa Chianese, Marcellino Monda, Marilena Galdiero, Gianluigi Franci

Department of Experimental Medicine, University of Campania Luigi Vanvitelli, Naples, Italy

\begin{abstract}
The emergence of multidrug resistant bacteria is a global health threat and the discovery of new antimicrobial agents is an absolute priority. In this context endogenous peptides are emerging as novel potential candidates. In this work, we assessed the antimicrobial effects of orexins and ghrelin neuropeptides against gram-negative (Escherichia coli, Salmonella typhimurium, Klebsiella pneumoniae) and gram-positive (Staphylococcus aureus) bacteria. Orexin-B and ghrelin showed a potent bactericidal effect at concentration equal to or greater than $25 \mu \mathrm{g} / \mathrm{ml}$. No antimicrobial activity has been observed for orexin-A. Furthermore, we investigated the antiviral proprieties of the three peptides against herpes simplex virus 1 (HSV-1). We found that orexin-B, but not orexin-A is effective for HSV-1 infectivity inhibition.
\end{abstract}

\section{Introduction}

Nowadays, antibiotics resistance is a major public health concern. The identification of new antimicrobial compounds is a top priority to face this situation. In this scenario neuropeptides are emerging as novel promising antimicrobial agents.

Synthesized in neurons, neuropeptides act as neurotransmitters in the central and peripheral nervous system. These peptides have a key role in the control of several biological processes included immune and inflammatory responses. ${ }^{1-3}$ In the recent past, some neuropeptides, such as the vasoactive intestinal polypeptide and neuropeptide $\mathrm{Y}$, have been reported having antimicrobial activities. ${ }^{4,5}$

In this work we explored both the antimicrobial and antiviral proprieties of orexins and ghrelin.

Orexin-A and orexin-B are neuropeptides produced in the lateral hypothalamus. ${ }^{6-}$ ${ }^{9}$ The two peptides are synthetized from a precursor, prepro-orexin, that is then cleaved to generate the active molecules. ${ }^{10-}$ 12 Orexin-A is a 33 amino acids peptide including 4 cysteines linked by two intrachain disulfide bonds. ${ }^{13,14}$ Post-translational modifications of this peptide include a pyroglutamyl cyclization at the N-terminal and a C-terminal amidation. Orexin-B is a 28 residue neuropeptide and like orexin- $\mathrm{A}$ is characterized by a C-terminal amidation. ${ }^{10,14}$ The two neuropeptides share $46 \%$ of sequence homology. ${ }^{10}$ Two-dimensional NMR spectroscopy analysis of soluble orexin-B revealed that its structure consists of two $\alpha$-helices linked via a flexible loop. ${ }^{10}$ The lateral hypothalamus, where the neuropeptides are generated, is responsible for eating behavior and energy homeostasis. ${ }^{6,15,16}$ Indeed, orexins play a key role in feeding behavior and body weight regulation, sympathetic activation, control of metabolic status and energy expenditure, sleep-wake cycles, ${ }^{17}$ and regulation of glucose level in the blood. ${ }^{6,18,19}$ These neuropeptides fulfill their functions interacting with two G-protein-coupled receptors (orexin receptor 1 and 2). ${ }^{6}$ Recently, orexin$\mathrm{B}$ has been reported having bactericidal effects. ${ }^{20}$

Another neuropeptide suggested to possess some antimicrobial activity is the appetite peptide ghrelin. ${ }^{21}$ Ghrelin, also known as lenomorelin, is 28-amino-acid $(3,3 \mathrm{kDa})$ peptide hormone that was first isolated and identified from rat stomach endocrine cells. ${ }^{22}$ It is produced mainly from the enteroendocrine cells in the mucosal layer of the stomach, ${ }^{23}$ but it was found also in the pancreas, kidney, small and large intestines ${ }^{24}$ and in salivary glands. ${ }^{25}$

The human Ghrelin gene (GHRL) encodes a 117 residue precursor (preproghrelin), that is cleaved by endoproteases to produce the mature ghrelin peptide. The ghrelin peptide exists in two forms acylated ghrelin and desacylated ghrelin, the functions of the latter are poorly understood. Ghrelin is characterized by the presence of an n-octanoyl group on the serine in third position (in some species on the threonine) that increases the hydrophobicity of the ghrelin molecule ${ }^{26}$ and it is important for the activity of the peptide. Ghrelin has been discovered as a natural ligand of the growth hormone secretagogue receptor. ${ }^{27}$ Increasing evidence supports a role for ghrelin in the regulation of hunger and metabolism. ${ }^{28}$ Ghrelin induces orexigenic signaling in the brain and regulates food intake, body weight and glucose metabolism. ${ }^{29}$ Moreover, this peptide boosts up the immune response ${ }^{20}$ and inhibits the production of proinflammatory cytokines. ${ }^{30}$
Correspondence: Gianluigi Franci, Department of Experimental Medicine, University of Campania Luigi Vanvitelli, Via Costantinopoli 16, 80138 Naples, Italy.

E-mail: gianluigi.franci@unicampania.it

Key words: Antibacterial; Antiviral; Neuropeptides; Orexins; Ghrelin.

Contributions: $\mathrm{CZ}$ and DS contributed equally; VF, LP, TFB, RA, AC, MM, MG, data collecting and manuscript reviewing and reference search; GF, data collecting, figures preparation and manuscript writing.

Conflict of interest: the authors declare no potential conflict of interest.

Funding: VALEREplus Program.

Received for publication: 28 February 2019. Accepted for publication: 13 March 2019.

This work is licensed under a Creative Commons Attribution 4.0 License (by-nc 4.0)

(C) Copyright C. Zannella et al., 2019

Licensee PAGEPress, Italy

Translational Medicine Reports 2019; 3:8142 doi:10.4081/tmr.8142

We investigated the antimicrobial activity of orexin-A, orexin-B and ghrelin against Escherichia coli, Salmonella typhimurium, Klebsiella pneumoniae and Staphylococcus aureus. Moreover, we evaluated the antiviral proprieties of the same peptides against herpes simplex virus 1 (HSV-1).

\section{Materials and Methods}

\section{Peptide synthesis}

Peptides were prepared by standard 9fluorenylmethoxycarbonyl polyamine solid-phase synthesis, using a PSSM8 multispecific peptide synthesiser (Shimadzu Corporation Biotechnology Instruments Department, Kyoto, Japan). The TGA resin (substitution $0.3 \mathrm{mmol} \mathrm{g}^{-1}$ ) was used as the solid-phase support, and syntheses were performed on a scale of $100 \mathrm{mmol}$. All amino acids, 4 equiv. relative to resin loading, were coupled according to the TBTU/HOBT/DIEA method: 1 equiv. of Fmoc-amino acid, 1 equiv. of TBTU, 1 equiv. of HOBT (1 M HOBT in DMF) and 2 equiv. of DIEA ( $2 \mathrm{M}$ DIEA in DMF). The Fmoc protecting group was removed with $30 \%$ piperidine in DMF (v/v). Peptides were fully deprotected and cleaved from the resin by hydrofluoric acid treatment: $89 \%$ 
trifluoroacetic acid (TFA) solution containing $5.5 \%$ thioanisole, $3.3 \%$ ethandithiol and $2.2 \%$ anisole as scavengers; the crude peptides were precipitated with ice-cold ethyl ether, filtered, re-dissolved in water and lyophilised. The crude peptides were purified to homogeneity by preparative reversephase high-pressure liquid chromatography (HPLC) on a Waters Delta Prep 3000 chromatographic system, equipped with an UV Lambda Max Mod. 481 detector. The samples were injected on a Jupiter (Phenomenex) C18 column $(21.20 \mathrm{~mm} \times 25$ $\mathrm{cm}, 15 \mu \mathrm{m}$ ) eluted with a $\mathrm{H}_{2} \mathrm{O} / 0.1 \%$ TFA (A) and $\mathrm{CH}_{3} \mathrm{CN} / 0.1 \%$ TFA (B) solvent mixture. A linear gradient from 20 to $75 \%$ of $\mathrm{B}$ over $55 \mathrm{~min}$ at a flow rate of $20 \mathrm{~mL} \mathrm{~min}{ }^{-1}$ was employed. The collected fractions were lyophilised to dryness and analysed by analytical reverse-phase HPLC on a Shimadzu class-LC10 equipped with a diode array detector SPD-M10AV using a Phenomenex C18 analytical column $(10 \times 250 \mathrm{~mm}, 10$ $\mu \mathrm{m})$; a linear gradient from 20 to $75 \%$ of B over $55 \mathrm{~min}$ at a flow rate of $1 \mathrm{~mL} \mathrm{~min}{ }^{-1}$ was used. The identity of purified peptides was confirmed by Maldi spectrometry. Their sequences, molecular weight and net charges are indicated in Table 1. All purified peptides were obtained with high yields $(50-60 \%)$.

\section{Cells and viruses}

African green monkey kidney cells (Vero) (ATCC CCL-81) were grown in Dulbecco's modified Eagle's medium (DMEM) supplemented with $10 \%$ fetal bovine serum. HSV-1 (strain SC16), carrying a lacZ gene driven by the CMV IE-1 promoter to express $\beta$-galactosidase, was propagated on Vero cells monolayers. The following bacterial strains were included in our study: the Gram-negative bacteria $E$. coli ATCC 11219, Pseudomonas aeruginosa ATCC 13388, Salmonella enterica serovar typhimurium ATCC 14028, and $K$. pneumoniae ATCC 10031 and the Grampositive bacterium $S$. aureus ATCC 6538 . To standardize the bacterial cell suspension for assay of antibacterial activity, some colonies of each strain grown overnight on MHA plates were resuspended in MHB and incubated at $37^{\circ} \mathrm{C}$ until visibly turbid. This $\log$-phase inoculum was resuspended in $0.9 \%$ sterile saline to reach an appropriate optical density at $600 \mathrm{~nm}$ (OD600) (with a Bio-Rad microplate reader; Bio-Rad Laboratories, Hercules, CA) corresponding to a concentration of about $1 \times 108 \mathrm{CFU} / \mathrm{ml}$. This standardized inoculum was diluted 1:10 in MHB, and the inoculum size was confirmed by colony counting.

\section{Antimicrobial-activity assay}

Susceptibility testing was performed using the broth microdilution method outlined by the Clinical and Laboratory Standards Institute using sterile 96-well microtiter plates (Falcon, NJ). Serial 2-fold dilutions (from 100 to $0,78 \mu \mathrm{g} / \mathrm{ml}$ ) of each peptide were prepared in cation-adjusted MHB at a volume of $100 \mu \mathrm{l} /$ well. Each well was inoculated with $5 \mu \mathrm{l}$ of the standardized bacterial inoculum, corresponding to a final test concentration of about $5 \times 10^{5} \mathrm{CFU} / \mathrm{ml}$. Antimicrobial activities were expressed as the $\%$ reduction of microbial growth observed after $24 \mathrm{~h}$ of incubation at $37^{\circ} \mathrm{C}$. Each assay was performed in triplicate, and the mean antimicrobial activity is reported.

\section{Virus entry assays}

Peptides were dissolved in DMEM without serum and used at serial 2-fold dilutions (from 100 to $0,78 \mu \mathrm{g} / \mathrm{ml}$ ). Experiments were conducted in parallel with scrambled peptides and no-peptide controls. To assess the effect of peptides on inhibition of HSV infectivity, a co-treatment assay was performed. The cells were incubated the peptides at each dilution in the presence of viral inoculum for $45 \mathrm{~min}$ at $37^{\circ} \mathrm{C}$. After inactivation of nonpenetrated viruses by citrate buffer ( $\mathrm{pH} 3.0$ ), cell monolayers were incubated for $48 \mathrm{~h}$ at $37^{\circ} \mathrm{C}$ in DMEM supplemented with carboxymethylcellulose. Finally, monolayers were fixed, stained with X-gal (5-bromo-4-chloro-3-indolyl-bD-galactopyranoside), and plaque numbers were scored. Experiments were performed in triplicate and the percentage of inhibition was calculated with respect to no-peptide control experiments.

\section{Cytotoxicity against eukaryotic cells}

Peptide cytotoxicity was measured by a lactate dehydrogenase (LDH) assay and was carried out according to manufacturer's instructions using a cytotoxicity detection kit (Roche Diagnostic SpA, Milan, Italy). Release of LDH from the cytosol to culture is a marker of cell death. The increase of LDH activity in the supernatant was related with the percentage of necrotic cells. Vero cells were cultured in a 96-well plate at a density of $3 \times 10^{4}$ cells/well for $24 \mathrm{~h}$, followed by treatment with investigated concentrations of each peptides for $24 \mathrm{~h}$. Maximal LDH release was obtained after the treatment of control cells with $1 \%$ solution of Triton X-100 (Sigma Chemical Company) for $10 \mathrm{~min}$ at room temperature. One hundred microliter of supernatant from the top of all the wells was mixed with the prepared detection kit reagent. After $30 \mathrm{~min}$ incubation, the absorbance (Abs) was measured at $490 \mathrm{~nm}$ by Tecan spectrophotometer plate. For each experiment, at least three replicate wells were examined.

\section{Hemolytic assay}

The hemolytic activity of the peptides was determined using fresh human erythrocytes from healthy donors. Blood was centrifuged and the erythrocytes were washed three times with $0.9 \% \mathrm{NaCl}$. Peptides were added to the erythrocyte suspension $(5 \%$, $\mathrm{vol} / \mathrm{vol}$ ) at a final concentration ranging from 0.78 to $100 \mu \mathrm{g} / \mathrm{ml}$ in a final volume of $100 \mu$ l. Samples were incubated with agitation at $37^{\circ} \mathrm{C}$ for $60 \mathrm{~min}$. The release of hemoglobin was monitored by measuring the Abs of the supernatant at $540 \mathrm{~nm}$. The control for zero hemolysis (blank) consisted of erythrocytes suspended in the presence of peptide solvent. Hypotonically lysed erythrocytes were used as a standard for $100 \%$ hemolysis. The percent hemolysis was calculated using the following equation: [(Abssample - Absblank)/(Abstotal lysis Absblank)] $\times 100$.

Table 1. Sequences, molecular weights and net charges of the peptides.

\begin{tabular}{llcc} 
Name & Sequence & NW (as TFA salt) & Net charge (pH 7) \\
\multirow{2}{*}{ Ghrelin } & $\begin{array}{l}\text { Gly-Ser-Ser(n-Octanoyl)-Phe-Leu-Ser-Pro-Glu-His-Gln-Arg-Val-Gln-Gln-Arg-Lys-Glu-Ser- } \\
\text { Orexin-B }\end{array}$ & 3370.9 & 5.1 \\
& $\begin{array}{l}\text { Arg-Ser-Gly-Pro-Pro-Gly-Leu-Gln-Gly-Arg-Leu-Gln-Arg-Leu-Leu-Gln-Ala-Ser-Gly-Asn-His- } \\
\text { Ala-Ala-Gly-Ile-Leu-Thr-Met-NH2 }\end{array}$ & 2899.36 & 4.1 \\
\hline \multirow{2}{*}{ Orexin-A } & $\begin{array}{l}\text { Gln-Pro-Leu-Pro-Asp-Cys-Cys-Arg-Gln-Lys-Thr-Cys-Ser-Cys-Arg-Leu-Tyr-Glu-Leu-Leu-His-Gly- } \\
\text { Ala-Gly-Asn-His-Ala-Ala-Gly-Ile-Leu-Thr-Leu-NH2 }\end{array}$ & 3561.12 & 1.9 \\
\hline
\end{tabular}

MW, molecular weights; TFA, trifluoroacetic acid. 


\section{Results}

\section{Antimicrobial-activity of orexins and ghrelin}

We assessed the antimicrobial activity of the synthesized peptides orexin-A, orexin-B and ghrelin on the bacterial strains $E$. coli, S. enterica serovar typhimurium, $K$. pneumoniae and $S$. aureus, following the broth microdilution method outlined by the Clinical and Laboratory Standards Institute. As shown in the Figure 1, a dose-dependent effect has been evidenced for orexin-B and ghrelin from concentrations equal to 12.5 $\mu \mathrm{g} / \mathrm{mL}$, or greater. In particular, at $25 \mu \mathrm{g} / \mathrm{ml}$ or higher concentrations of orexin-B or ghrelin the relative $\%$ of viable bacteria was minimal, revealing a potent antimicrobial effect. Moreover, the results obtained for orexin-B and ghrelin are in accordance with what has been reported previously reported for $E$. coli, ${ }^{20}$ whereas $S$. aureus, tested with the broth microdilution method, resulted sensitive. In contrast, no bacterial killing effect has been observed for orexin-A, tested on the four bacterial strains.

\section{Anti-viral proprieties of orexin-B}

The ability of the peptides to reduce HSV-1 infectivity has been evaluated by a co-treatment assay. As negative control we included the medium in which the peptides have been dissolved (vehicle) and as positive control the cytolytic peptide mellitin. As shown in Figure 2, only for orexin-B a significative, dose-dependent antiviral effect has been found. The effect started at $25 \mu \mathrm{g} / \mathrm{mL}$, exceeding the IC 50 value at 100 $\mu \mathrm{g} / \mathrm{mL}$. No antiviral effect has been detected for orexin-A and ghrelin at the tested concentrations.

\section{Cytotoxicity of orexins and ghrelin}

As shown in Table 2, orexin-A, orexin$\mathrm{B}$ and ghrelin are not cytotoxic. However,
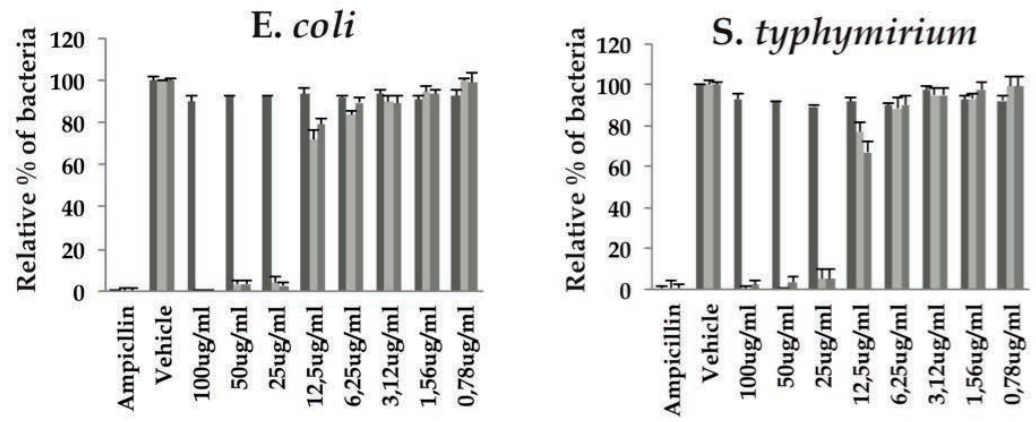

\section{Orexin A Orexin B $\square$ Ghrelin}
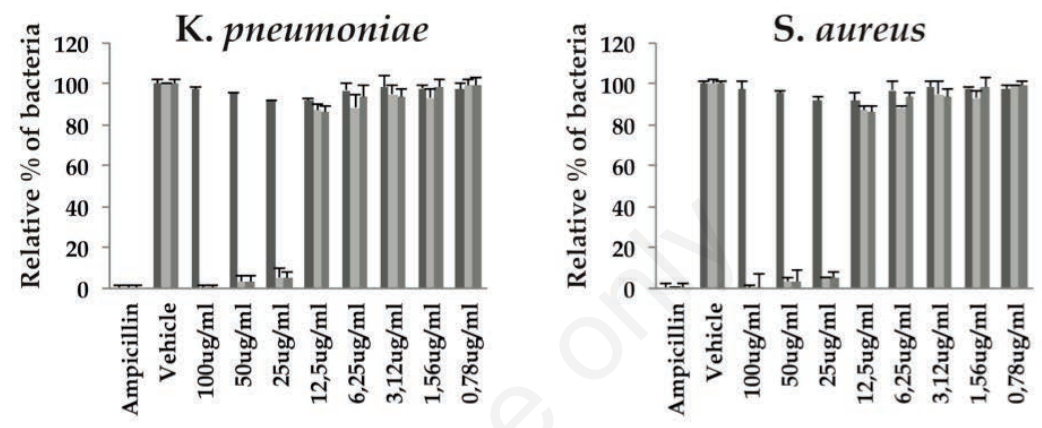

Figure 1. Histogram of antibacterial activities of orexin-A, orexin-B and ghrelin expressed in $\%$.

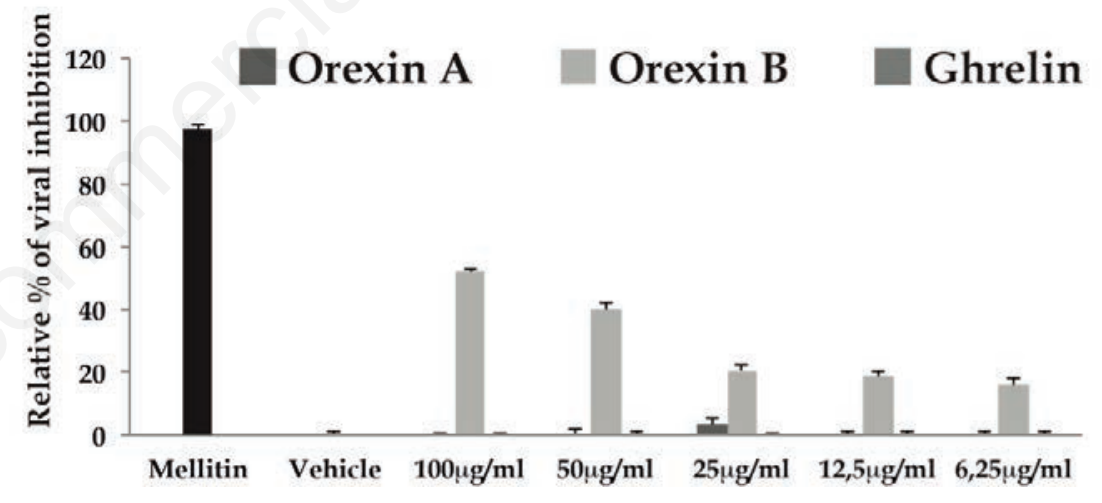

Figure 2. Histogram of relative $\%$ of viral inhibition of herpes simplex virus 1 infection.

Table 2. Cell viability and hemolysis caused by exposure to different concentration of peptides orexin-A, orexin-B and ghrelin. Cell viability is expressed as percentage of lactate dehydrogenase released compared to a positive control (Vero cells treated with a $1 \%$ solution of Triton X-100 for $10 \mathrm{~min}$ at room temperature). Hemolysis is expressed as percentage of released hemoglobin respect to a positive control made of hypotonically lysed erythrocytes. All experiments were conducted in triplicate.

\begin{tabular}{|c|c|c|c|c|c|c|}
\hline \multirow{2}{*}{ Peptide concentrations ( $\mu \mathrm{g} / \mathrm{ml})$} & \multicolumn{3}{|c|}{ Cell viability (\%) } & \multicolumn{3}{|c|}{ Hemolysis (\%) } \\
\hline & Orexin-A & Orexin-B & Ghrelin & Orexin-A & Orexin-B & Ghrelin \\
\hline 100 & 92 & 89 & 91 & 16 & 8 & 15 \\
\hline 50 & 94 & 96 & 95 & 11 & 2 & 9 \\
\hline 25 & 100 & 100 & 97 & 1 & 0 & 2 \\
\hline 12,5 & 100 & 100 & 100 & 0 & 0 & 0 \\
\hline 6,25 & 100 & 100 & 100 & 0 & 0 & 0 \\
\hline 3,125 & 100 & 100 & 100 & 0 & 0 & 0 \\
\hline 1,56 & 100 & 100 & 100 & 0 & 0 & 0 \\
\hline 0,78 & 100 & 100 & 100 & 0 & 0 & 0 \\
\hline
\end{tabular}


we observed a slight reduction of cell viability in Vero cells at the highest concentrations tested $(50-100 \mu \mathrm{M})$. The difference between the cytotoxic effects of the three peptides was mild, and slightly more marked only at $100 \mu \mathrm{M}$, where orexin-B was found to be the most endowed with a mild cytotoxic effect.

The results of the hemolityc assays are reported in Table 2. The peptides do not induce hemolysis at concentrations less than $25 \mu \mathrm{M}$. A modest hemolityc effect appears at 50 and $100 \mu \mathrm{M}$ concentrations for all three peptides.

\section{Discussion and Conclusions}

In the last years several endogenous peptides have been reported having antimicrobial activity, and among these some neuropeptides. It has been suggested that these cationic peptides bind to the negatively charged bacterial cell wall exerting their antimicrobial effect. In line with this, orexins sequence is rich in positive charged residues. ${ }^{20}$

In this study we assessed the antimicrobial activity of orexin-A and orexin-B against the gram-negative E. coli, S. thyphimurium and $K$. pneumoniae and the gram-positive $S$. aureus.

Orexins share $46 \%$ of sequence homology, despite this only orexin-B showed antimicrobial proprieties.

We found that orexin-B was effective against all the strains tested. Our results are consistent with the results of Ohta et al. reporting bactericidal activity of orexin-B against $E$. coli and $P$. aeruginosa. ${ }^{20}$ Furthermore, we assessed the antiviral activity of these neuropeptides against HSV-1. Orexin-B showed a dose-response antiviral effect, exceeding the IC 50 value at $100 \mu \mathrm{g} / \mathrm{mL}$. On the other hand, ghrelin did not show antiviral activity at the assessed concentrations. However, it was effective against all the gram positive and gram negative tested bacteria. Ghrelin, like orexin-B, is a cationic peptide and shows a similar isoelectric point and it has been suggested that it could share the same bactericidal mechanism. ${ }^{21}$ Further studies are required to investigate the mechanism underlying the anti-viral activity of orexin-B. However, taken together our results indicate that neuropeptides represent promising candidates as both antiviral and anti-bacterial agents.

\section{References}

1. Souza-Moreira L, Campos-Salinas J,
Caro M, Gonzalez-Rey E. Neuropeptides as pleiotropic modulators of the immune response. Neuroendocrinology 2011;94:89-100.

2. Delgado M, Ganea D. Anti-inflammatory neuropeptides: a new class of endogenous immunoregulatory agents. Brain Behav Immun 2008;22:1146-51.

3. Gonzalez-Rey E, Delgado M. Antiinflammatory neuropeptide receptors: new therapeutic targets for immune disorders? Trends Pharmacol Sci 2007;28:482-91.

4. El Karim IA, Linden GJ, Orr DF, Lundy FT. Antimicrobial activity of neuropeptides against a range of micro-organisms from skin, oral, respiratory and gastrointestinal tract sites. J Neuroimmunol 2008;200:11-6.

5. Brogden KA, Guthmiller JM, Salzet M, Zasloff $M$. The nervous system and innate immunity: the neuropeptide connection. Nat Immunol 2005;6:558-64.

6. Messina G, Dalia C, Tafuri D, et al. Orexin-A controls sympathetic activity and eating behavior. Front Psychol 2014;5:997.

7. Burdakov D, Gonzalez JA. Physiological functions of glucoseinhibited neurones. Acta Physiol (Oxf) 2009; 195:71-8.

8. Cowley MA, Smith RG, Diano S, et al. The distribution and mechanism of action of ghrelin in the CNS demonstrates a novel hypothalamic circuit regulating energy homeostasis. Neuron 2003;37:649-61.

9. Boss C, Roch C. Recent trends in orexin research-2010 to 2015. Bioorg Med Chem Lett 2015;25:2875-87.

10. Lee JH, Bang E, Chae KJ, et al. Solution structure of a new hypothalamic neuropeptide, human hypocretin2/orexin-B. Eur J Biochem 1999;266: 831-9.

11. Lang M, Soll RM, Durrenberger F, et al. Structure-activity studies of orexin a and orexin B at the human orexin 1 and orexin 2 receptors led to orexin 2 receptor selective and orexin 1 receptor preferring ligands. J Med Chem 2004;47:1153-60.

12. Chieffi S, Carotenuto M, Monda V, et al. Orexin system: the key for a healthy life. Front Physiol 2017;8:357.

13. Okumura T, Takeuchi S, Motomura W, et al. Requirement of intact disulfide bonds in orexin-A-induced stimulation of gastric acid secretion that is mediated by OX1 receptor activation. Biochem Biophys Res Commun 2001;280:97681.

14. Sakurai T, Amemiya A, Ishii M, et al. Orexins and orexin receptors: a family of hypothalamic neuropeptides and $\mathrm{G}$ protein-coupled receptors that regulate feeding behavior. Cell 1998;92:573-85.

15. Nakazato M, Murakami N, Date Y, et al. A role for ghrelin in the central regulation of feeding. Nature 2001;409:194-8.

16. Tolle V, Bassant MH, Zizzari P, et al. Ultradian rhythmicity of ghrelin secretion in relation with $\mathrm{GH}$, feeding behavior, and sleep-wake patterns in rats. Endocrinology 2002;143:1353-61.

17. Hoyer D, Jacobson LH. Orexin in sleep, addiction and more: is the perfect insomnia drug at hand? Neuropeptides 2013;47:477-88.

18. Messina G, Viggiano A, De Luca V, et al. Hormonal changes in menopause and orexin-a action. Obstet Gynecol Int 2013;2013:209812.

19. Rani M, Kumar R, Krishan P. Role of orexins in the central and peripheral regulation of glucose homeostasis: Evidences \& mechanisms. Neuropeptides 2018;68:1-6.

20. Ohta K, Kajiya M, Zhu T, et al. Additive effects of orexin $\mathrm{B}$ and vasoactive intestinal polypeptide on LL-37-mediated antimicrobial activities. J Neuroimmunol 2011;233:37-45.

21. Wilcox T, Hirshkowitz A, Hawkins L, Boas DA. The effect of color priming on infant brain and behavior. Neuroimage 2014;85:302-13.

22. Kojima M, Hosoda H, Date Y. Ghrelin is a growth-hormone-releasing acylated peptide from stomach. Nature 1999;402:656-60.

23. Date $Y$, Kojima M, Hosoda $H$, et al. Ghrelin, a novel growth hormonereleasing acylated peptide, is synthesized in a distinct endocrine cell type in the gastrointestinal tracts of rats and humans. Endocrinology 2000;141:4255-61.

24. Sakata I, Sakai T. Ghrelin cells in the gastrointestinal tract. Int $\mathrm{J}$ Pept 2010;2010.

25. Groschl M, Topf HG, Bohlender J, et al. Identification of ghrelin in human saliva: production by the salivary glands and potential role in proliferation of oral keratinocytes. Clin Chem 2005;51:9971006.

26. Bednarek MA, Feighner SD, Pong SS, et al. Structure-function studies on the new growth hormone-releasing peptide, ghrelin: minimal sequence of ghrelin necessary for activation of growth hormone secretagogue receptor 1a. J Med Chem 2000;43:4370-6.

27. Kojima M, Hosoda $\mathrm{H}$, Matsuo $\mathrm{H}$, Kangawa K. Ghrelin: discovery of the natural endogenous ligand for the growth hormone secretagogue receptor. 
Trends Endocrinol Metab 2001;12:118- 29. Chabot F, Caron A, Laplante M, St22.

28. Muller TD, Nogueiras R, Andermann $\mathrm{ML}$, et al. Ghrelin. Mol Metab 2015;4:437-60. Pierre DH. Interrelationships between ghrelin, insulin and glucose homeostasis: Physiological relevance. World J Diabetes 2014;5:328-41.
30. Dixit VD, Schaffer EM, Pyle RS, et al Ghrelin inhibits leptin- and activationinduced proinflammatory cytokine expression by human monocytes and $\mathrm{T}$ cells. J Clin Invest 2004;114:57-66. 